\section{Military Technical College \\ Kobry El-Kobbah, Cairo, Egypt}

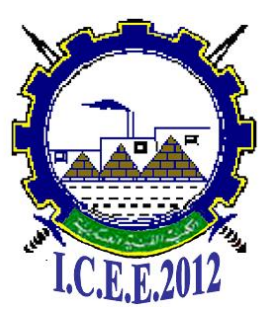

$6^{\text {th }}$ International Conference on

Chemical \& Environmental Engineering

29 -31 May, 2012.

NRSW -2

\title{
DEVELOPMENT OF NUCLEAR SAFETY CONCEPTS AND MEASURES
}

\author{
Sayed A. EL- Mongy *
}

\begin{abstract}
:
Nuclear safety goes back to beginning of the nuclear era, specifically during the II World war. At that time, 1942, Enrico Fermi used control rods of coated cadmium to check and control the first chain nuclear fission reaction. The abbreviation SCRAM (safety control rods axe man) was invented and applied on the first nuclear Pile reactor. Recently, it represents the automatic shutdown or reactor trip in the case of pressurized water reactor (PWR).

With introducing nuclear reactors for research, commercial electricity production and military applications; nuclear safety was developed step by step from reactors generation to another. After Chernobyl accident 1986, abrupt changes in the nuclear safety world have been considered. Nowadays with certification and construction of Generation III+ reactors, major revolutionary safety measures are fully adopted, accepted and established. Passive (e.g. gravity and natural circulation) with active (e.g enhanced electrical and mechanical) safety system approaches are currently available and applicable in advanced reactors.

The Terminologies such as defense in depth concept, inherently safe, ,negative temperature coefficient, emergency core cooling system, core catcher ,minimizing core damage frequency, pressure suppression system, containment heat removal system ,human machine interface ( HMI), robustness / aircraft crashes resistant, proliferation resistant, increased peak ground acceleration factor and many other are being vital, essential and targeted vocabularies of nuclear safety dictionary. The fourth generation IV of power reactors is in the drawing phase. They will be fully controlled by passive natural measures. Nuclear fusion reactors are expected to be a non-depleted commercial power source of energy in the next decades.

As a matter of fact, there are about 440 nuclear power plants. They supply the world with about $16 \%$ of electricity. To reflect the importance of nuclear energy for the benefit of human being, Japan after Fukushima accident 2011, increased its safety measures without stopping their nuclear programs. South Korea plans to get $59 \%$ of its electricity by nuclear energy.
\end{abstract}

\footnotetext{
* Head of Nuclear Safeguards \& Physical Protection Department Nuclear and Radiological Regulatory Authority (NRRA) Email: sayedelmongy@hotmail.com
} 